\title{
FDA says study overestimated non-compliance with data-reporting laws
}

\author{
US drug regulator finds no evident harm caused by sponsors failing to post drug-trial data.
}

Meredith Wadman

01 May 2012

WASHINGTON DC

The US Food and Drug Administration (FDA) and National Institutes of Health have disputed charges that sponsors are under-reporting clinical-trial results. The letters to Congress, obtained by Nature under the Freedom of Information Act, come in response to questions raised after a study in the British Medical Journal $(B M J){ }^{1}$, reported that, in 2009 , only $22 \%$ of trial sponsors posted their results within one year of completion, as the law requires.

The provision of the FDA Amendments Act seemed simple enough when it was passed in 2007: sponsors of clinical trials of alreadyapproved drugs would be required to post their results in a public database. That database, ClinicalTrials.gov, maintained by the $\mathrm{NIH}$, would be the user-friendly storehouse for detailed information on all but the earliest, phase I, safety trials of drugs, devices and biologics.

But after the BMJ study was published in January, members of the US Congress, led by Representative Henry Waxman, demanded an explanation from the $\mathrm{NHH}$ and the Food and Drug Administration (FDA), which are jointly responsible for enforcing the law. Waxman is the ranking member of the House Energy and Commerce Committee, which has jurisdiction over the two agencies.

In its response, the FDA says that the analysis included some trials that were completed before the law came into effect, and did not exclude those - such as uncontrolled trials that are exempt from the reporting requirements. Nor did the authors exclude all trials of unapproved products, which at present are excluded from the law. The authors, in addition, included some trials for which data had been submitted but not yet vetted by $\mathrm{NIH}$.

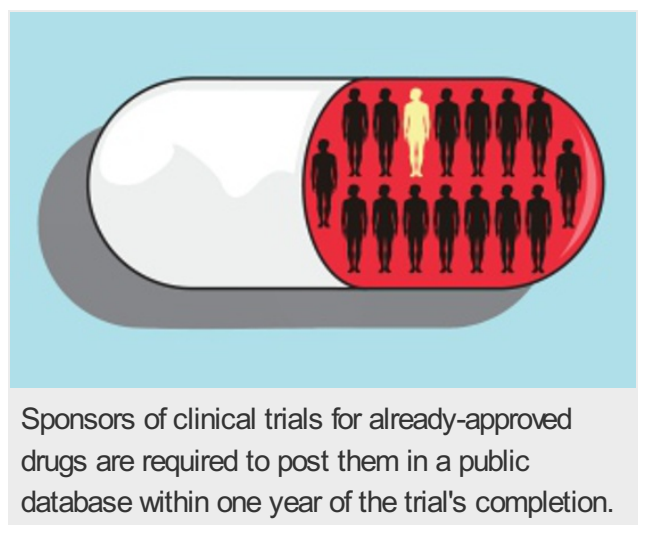
Finally, the BMJ authors could not tell, from the data in ClinicalTrials.gov, whether a sponsor's submission deadline had been extended; the law allows this when an approved product is being tested for a new indication.

In all, Jeanne Ireland, the FDA's assistant commissioner for legislation, wrote that, after combing ClinicalTrials.gov and reviewing other information available only to the FDA, the regulator is "pursuing individual responsible parties" in 15 cases for failing to post results on time. The total number of trials that "appear" to fall under the reporting requirement was 7,881 as of May 2011, according to an unofficial estimate provided to Nature by $\mathrm{NHH}$. She added that there was "no evidence" that any purported delay in data posting has resulted in useless or dangerous drugs remaining on the market.

The NIH's unofficial analysis does agree with the BMJ study in one important respect: companies are outperforming their governmental and academic counterparts. On-time reporting rates were $52 \%$ for industry, $21 \%$ for $\mathrm{NIH}$-based sponsors and $14 \%$ for $\mathrm{NIH}$-funded academic sponsors. 
"The academic world is probably doing a worse job of reporting than industry," says Deborah Zarin, director of ClinicalTrials.gov. "And that's consistent with what BMJ found."

Andrew Prayle, an author of the BMJ paper and a clinical research fellow at the University of Nottingham, UK, says that it is not surprising that the FDA reached different conclusions on the basis of information to which it alone has access.

"There remain two key questions," says Prayle. "First, can they account for all of the $78 \%$ of trials which had not reported? We felt that this was unlikely. And second, why is it so hard to establish if a trial falls under the regulations?"

Waxman's office says that the Energy and Commerce Committee is "continuing to evaluate" the NIH and FDA responses.

In his letter to Waxman, NIH director Francis Collins said that the submission of trial results is "critically important" and that rules interpreting the law, to be released by the agencies later this year, should clarify the requirements and "significantly improve" compliance. Those rules will pronounce on a key issue which the law left unsettled: whether data on drugs and devices not yet approved by the FDA should also be posted in ClinicalTrials.gov.

The FDA's letter to Waxman comes as the Institute of Medicine (IOM), the health arm of the non-profit National Academies based in Washington DC, today releases a report on how the FDA can improve the safety of drugs already on the market. The report was spurred by revelations in 2007 that the diabetes drug Avandia (rosiglitazone) presents serious heart-attack risks.

The IOM says that the FDA's oversight of marketed drugs "is not sufficiently systematic and does not ensure consistent assessment of benefits and risks associated with a drug over its lifecycle."

The report's leading recommendation calls on the agency to create a benefit and risk assessment and management plan for every drug it approves - a user-friendly, publicly available document that would capture information about a drug before it is approved and throughout its time on the market. The document, the authors write, should flag safety questions that exist when a drug is approved and that emerge once it is on the market, and should catalogue regulatory actions taken by the FDA, from label changes to demands for further randomized clinical trials.

Nature | doi:10.1038/nature.2012.10549

\section{References}

1. Prayle, A. P., Hurley, M. N. \& Smyth, A. R. Br. Med. J. http://dx.doi.org/10.1136/bmj.d7373 (2012).

\section{SPRINGER NATURE}

